\title{
Las series de televisión \\ y la enseñanza de la Historia
}

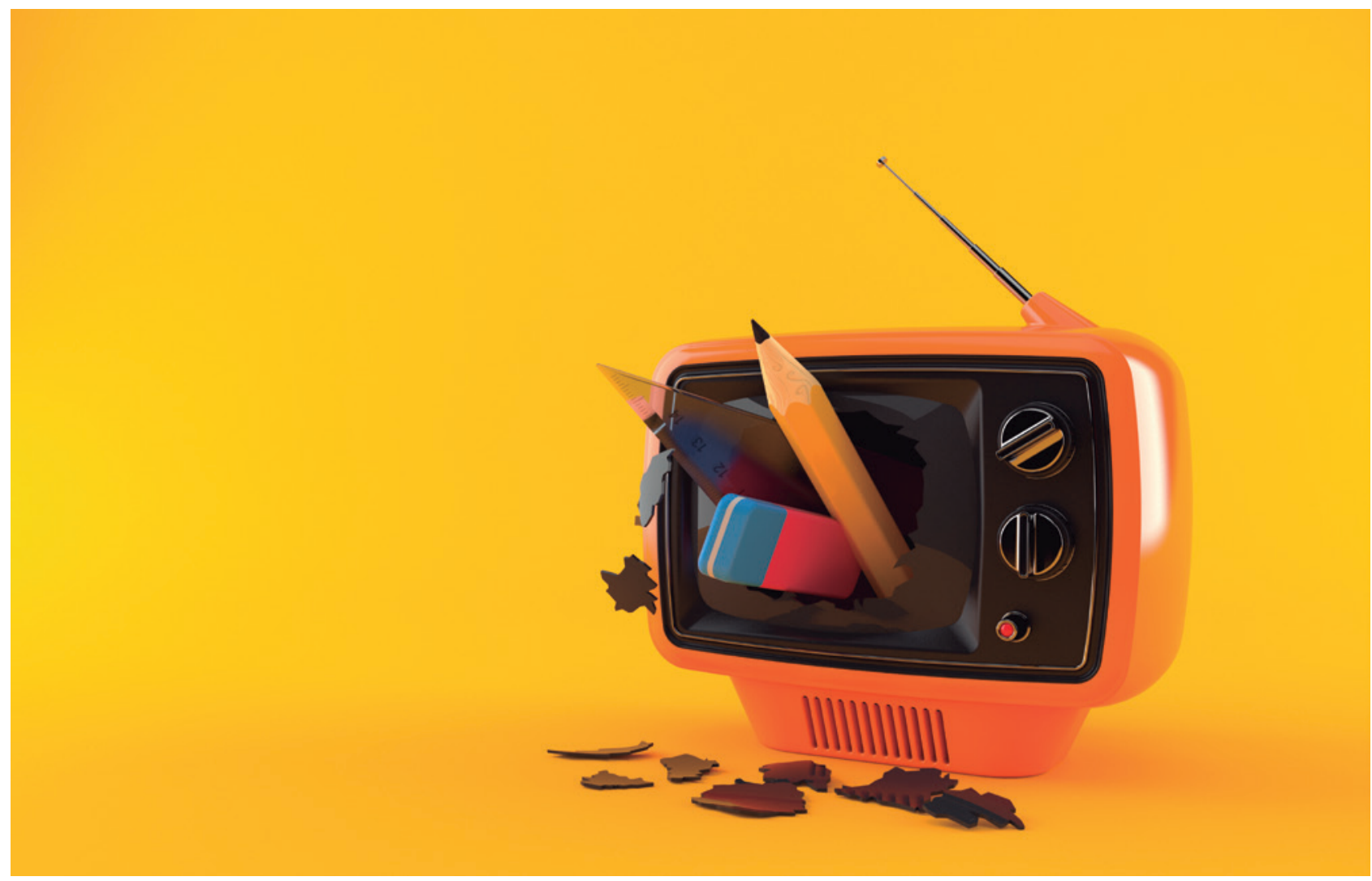

En los últimos años hemos observado la aparición de un importante número de series de televisión que buscan acercar al gran público el conocimiento de nuestra historia. Productos mediáticos con gran poder de influencia en el imaginario de sus espectadores, así como en la creación de estereotipos. Este artículo pretende reflexionar en torno al papel que los productos televisivos de pretendido carácter histórico pueden jugar en el conocimiento de la gente, así como sobre la utilidad de este modo de aproximación al conocimiento histórico. 
de series documentales de temática histórica de gran predicamento en aquellos primeros lustros.

En palabras de Durán Froix:

Ningún otro medio moderno de comunicación social había, hasta entonces y durante un periodo tan amplio, dedicado tanto empeño, tiempo y asiduidad al pasado. Entre 1966 y el avenimiento de la democracia, no transcurrió prácticamente una semana, sin que el pasado estuviese presente, por lo menos una vez $-\mathrm{y}$ a menudo varias—, en las pantallas españolas.

En los años 70 continuó este interés y pudimos disfrutar de series como Poldark, en la que se repasaban los principales hechos sociales e históricos del Reino Unido en el siglo XVIII y primeros años del XIX; Yo, Claudio, icónica serie que rememoraba la historia del Imperio Romano entre Octavio Augusto y el propio Claudio o El pícaro, producción que mostraba a los españoles las andanzas y desventuras de Lucas de Trapaza, un picaruelo de la España del XVI.

A lo largo de las dos siguientes décadas las series de temática histórica retrocedieron algo en la parrilla televisiva española, que se inclinó más por las Ilamadas sitcom - comedias de situación. Series como Frasier, El príncipe de Bel-Air, Friends, Las Chicas de oro, Los ladrones van a la oficina, Siete Vidas o Farmacia de Guardia protagonizaron de manera indiscutible estos años. No obstante, algunas producciones de temática histórica o pseudohistórica también supieron hacerse su hueco con títulos como Fortunata y Jacinta, Berlín Alexanderplatz o La forja de un rebelde.

Ya en el siglo XXI hemos asistido a una explosión de la oferta televisiva a través de decenas de canales accesibles a través de multitud de plataformas de pago que han venido a competir con televisiones privadas en abierto, cadenas nacionales y autonómicas y una creciente oferta de televisión vía internet. Esa oferta televisiva, como cabía esperar, ha ido concretándose en canales temáticos enfocados a públicos específicos: desde el apasionado de la cocina, al amante de los deportes, el aficionado a los animales o el interesado en la historia, todos encuentran respues-

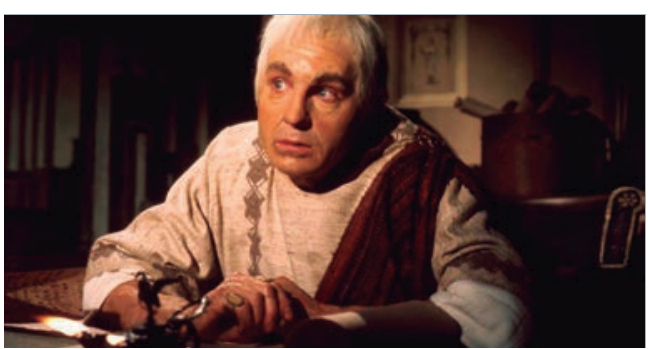

La serie de la BBC Yo, Claudio, emitida en 1976 por TVE es uno de los mejores productos televisivos de la historia. Basada en dos novelas del británico

Robert Graves,

nos ilustra en los

principales hechos de los reinados de Augusto y Tiberio

ta a sus aficiones y pasiones en la actual oferta audiovisual.

En paralelo a esta multiplicidad de opciones, hemos asistido también a una nueva explosión del interés, tanto por parte del gran público como de los ejecutivos de las cadenas, en la oferta de grandes series con temática histórica. En los últimos años, millones de personas se han acercado a la historia a través de las referencias ofrecidas por producciones como Cuéntame, Downton Abbey, Roma, Los Tudor, Águila Roja, Carlos Emperador, Hijos de/ /// Reich, El Ministerio del Tiempo y tantas otras.

La expansión televisiva de este tipo de producciones evidencia el creciente interés de los televidentes por asomarse a cierto conocimiento de la historia de una manera fácil, placentera, prácticamente recreativa. No podemos olvidar que, en palabras de Rosenstone:

Hoy en día, la gran fuente de conocimiento histórico de la mayoría de la población — fuera del despreciado libro de texto- seguramente son los medios visuales, un conjunto de instituciones cuyo control está casi completamente fuera del alcance de aquellos de nosotros que dedicamos nuestras vidas a la historia.

\section{Validez didáctica de las series de televisión}

Hemos constatado el gran interés que tanto las televisiones como los espectadores han mostrado siempre en la emisión y consumo de series enfocadas a temáticas históricas de todo tipo, pero ison estos productos recursos didácticos apropiados para la enseñanza y el aprendizaje de la historia? No podemos obviar que este tipo de ficciones históricas "crean" una realidad no "son" la realidad misma, dado que, habitualmente, son concebidos 
Como ejemplo de lo desarrollado en el presente artículo se propone aquí el uso de la serie Isabe/ para explicar los hechos históricos más importantes del reinado de los Reyes Católicos. Podemos acceder a ella, de una manera sencilla y gratuita, en el siguiente enlace: https://www.rtve.es/television/isabel-la-catolica/, Sus primeros capítulos nos ofrecen la posibilidad de repasar el reinado de Enrique IV, hermanastro de Isabel I de Castilla, el problema sucesorio, la política de alianzas matrimoniales, la guerra civil por la sucesión al trono 0 a los principales personajes de la Corte castellana de la segunda mitad del siglo XV.

Para aprovechar mejor el visionado de los distintos fragmentos seleccionados propondremos a los alumnos que respondan a las siguientes preguntas: ¿en qué siglo y lugares se desarrollan los hechos? ¿Eres capaz de nombrar a ocho de los principales personajes que aparecen en la trama y el papel que juegan en ella? ¿Qué moneda se utilizaba en el siglo XV? ¿Cuál era el principal papel de las mujeres de la época? ¿Cuántos reinos había en la península ibérica en los años en que se desarrolla la serie? ¿Con qué personajes quisieron casar a Isabel antes de su matrimonio con Fernando de Aragón? ¿Quiénes, además del rey, tomaban entonces las decisiones? ¿Consideras que era un sistema democrático? ¿De qué manera podía influir la Iglesia en las decisiones políticas de la época?

Con estas preguntas contribuiremos a que los alumnos observen minuciosamente las distintas proyecciones que les ofrezcamos, ya que la necesidad de contestar a ellas centrará su atención en las cuestiones que les proponemos.

Por último, propondremos la creación de un mapa conceptual en el que iremos colocando a los principales personajes que hayamos repasado así como la relación entre ellos y sus principales características y ambiciones personales.

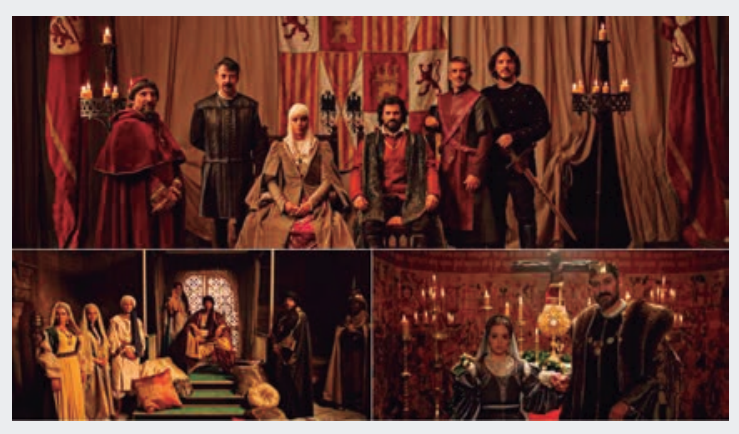

como productos de gran consumo con vocación de alta rentabilidad económica, no de rigurosidad histórica y educación de su público. No hay que esperar que la exhibición histórica que se realiza en ellas represente de manera fidedigna lo que ocurrió. La mayor parte de estas series diluyen lo histórico con otras tramas, habitualmente sentimentales, que persiguen la fidelización de los espectadores, quienes suelen desarrollar sentimientos subjetivos por los protagonistas de estas ficciones. Esos sentimientos, ya de simpatía, ya de repulsa, de admiración por su trabajo, de atracción física o de cual- quier otra naturaleza, positiva o negativa, pueden enturbiar el conocimiento y la reflexión sobre la realidad de lo que pudiera suceder en los acontecimientos narrados.

Por motivos como estos, el uso de estos recursos ha generado habitualmente desconfianza en muchos investigadores, historiadores y docentes pero estas producciones no deberían ser apartadas sin más pues en ellas podemos encontrar, conociendo sus limitaciones, defectos y particularidades, aspectos aprovechables para la enseñanza.

Muchas están realizadas con un alto rigor histórico, asesoradas por historiadores especialistas en la época que procuran un producto de calidad y, además de la imprescindible rentabilidad económica, buscan la excelencia y la formación del espectador.

Un buen ejemplo de esto sería la exitosa serie /sabel, un producto de calidad, con el que se instruyó a millones de españoles en la vida de la reina Isabel la Católica tras un proceso de documentación de más de dos años por parte de sus guionistas y directores.

Los momentos históricos que se van mostrando, la caracterización de los personajes, los cuidados vestuarios, los seleccionados exteriores, etc., todo suma para mostrar un producto excelente (con algunas licencias de guion, claro está) que, además de amenizar, contribuye a crear un interés en los espectadores por el periodo en el que se desarrollan sus tramas.

\section{¿Cómo usar una serie como recurso didáctico?}

Antes de comenzar a preparar la enseñanza de un contenido a través del uso de una serie es imprescindible tener muy clara la metodología a emplear. Por supuesto, esta dependerá del tipo de resultados que queramos obtener: ipretendemos trabajar sobre los hechos bélicos de una época en concreto? ¿Profundizar en el conocimiento de determinado personaje? ¿Conocer los usos y costumbres de un periodo? Hay muchísimas posibilidades, desde realizar un análisis de la evolución de la vestimenta de las distintas clases 


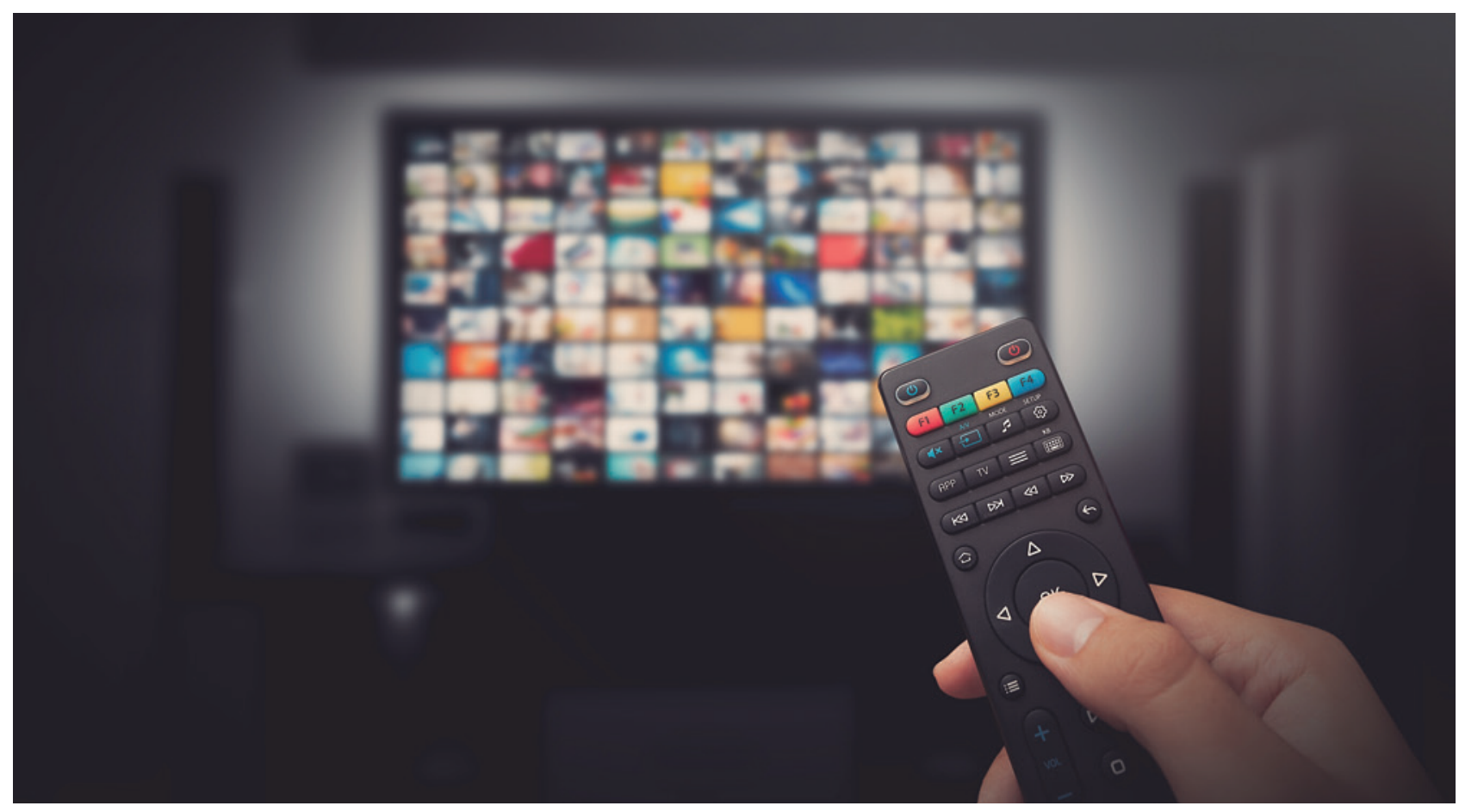

sociales, del lenguaje o de las mentalidades hasta analizar el papel de las mujeres, conocer mejor los nombres más destacados de un momento histórico concreto o poner imagen a los lugares en los que se desarrollaban los hechos estudiados.

Todo esto, claro, cuando la serie es de calidad y no desatiende en demasía el rigor histórico. Es por ello que otro paso fundamental es ser escrupuloso y exigente en la selección del producto con el que pretendemos trabajar. No todo nos va a valer. Es más, será más lo que debamos descartar que lo aprovechable. Por ello, el visionado previo, atento y detallado por parte del profesor resulta indispensable.

Asimismo, es deseable que el profesor esté bien documentado acerca de lo que se cuenta en la proyección que va a llevar al aula, tanto para fiscalizar la buena calidad de la información que en ella se ofrezca como para realizar las aclaraciones complementarias que sean necesarias. Un producto televisivo con un buen rigor histórico no deja de ser algo concebido para el entretenimiento del gran público, condicionado por los tiempos y las estrategias comunicativas propias del medio y, como consecuencia de todo ello, susceptible de distintas inexactitudes que deberán ser localizadas y aclaradas por el docente.

Debemos considerar también que la atención del alumnado se disperse en cuestiones que no son las que nos intere-
Resulta necesario hacer un detallado

seguimiento de estas producciones, analizando

su mensaje, seleccionando aquellas que dan

al rigor y al conocimiento un peso sustancial en

sus relatos

sa trabajar al usar este recurso, por lo que sería interesante guiarles un poco a través de la entrega de alguna ficha con preguntas que deberán ser respondidas tras el visionado. El hecho de tener que contestar esas cuestiones contribuirá a que fijen su atención en aquello que más nos importe que aprendan tras la actividad.

Otra posibilidad es escoger algunos momentos especialmente destacados de la trama narrada y usarlos para proponer a los alumnos un estudio más profundo de los mismos. También podríamos proponer una línea del tiempo que iríamos rellenando con los principales hechos que observemos durante el visionado.

Sería importante, asimismo, que el profesor entregue a los alumnos una lista, a modo de fe de erratas, con las inexactitudes o errores que haya observado previamente en la proyección que vaya a trabajar en el aula. Esto, además 


\section{La labor del docente se muestra indispensable para hacer un buen uso de las posibilidades de este recurso. Deberá señalar sus fallos e inexactitudes ante el alumnado y proponer modelos de análisis y trabajo con estos materiales audiovisuales}

de contribuir al aprendizaje más riguroso de los hechos, ayudará también a desarrollar una visión crítica en el alumnado, al hacerle más consciente de que estos productos no son la historia misma, por muy bien realizados que estén. Si conseguimos con esto aumentar la exigencia del alumnado en el consumo de estos productos, habrá merecido la pena.

\section{Conclusiones}

Es frecuente que nuestros alumnos conciban la historia como algo arduo, puramente memorístico, aburrido o, incluso, inútil. Sabemos lo alejadas de la realidad que están estas opiniones, pero existen y son habituales, por lo que los que nos dedicamos a su enseñanza y difusión tenemos el permanente reto de disolver tales prejuicios demostrando que la historia no solo tiene interés y utilidad sino que, además, su estudio y conocimiento puede llegar a ser muy grato y placentero.

Un reto para cuyo cumplimiento debemos hacer uso de todos los recursos

\section{(ద.) DคRि SABER MÂS}

Moral, E. DEL (coord.) (2010). Televisión: desarrollo de la creatividad e infancia. Barcelona: Octaedro.

Rosenstone, R. A. (2005). La historia en imágenes, la historia en palabras. Istor (20), 91-108.

SARTORI, G. (1998): Homo videns. La sociedad teledirigida. Madrid: Taurus. a nuestro alcance $y$, de entre ellos, los medios de comunicación se cuentan entre los más interesantes. Archivos, bibliotecas y museos son aliados académicos de primer orden e incuestionable calidad, pero también debemos admitir que suelen ser percibidos por nuestro alumnado como algo lejano, laborioso e, incluso, frío.

Los productos audiovisuales, por el contrario, son percibidos como algo mucho más vinculado a su realidad, más cercano, más asequible y entretenido. Un recurso, sin duda, con varios posibles defectos, de calidad impar y más vocación comercial que didáctica. Un producto de masas rara vez concebido para especialistas pero con un innegable potencial, altísima capacidad de transmisión de su mensaje y, siempre que sea bien trabajado por el profesor, muy adecuado como medio de aprendizaje complementario a nuestras explicaciones.

La labor del docente se muestra, por lo tanto, indispensable para hacer un buen uso de las posibilidades de este recurso y minimizar sus defectos. En ningún caso su labor acabará con la selección y proyección del mismo, sino que deberá actuar como permanente notario de la calidad del producto, señalar sus fallos e inexactitudes ante el alumnado y proponer modelos de análisis y trabajo con estos materiales audiovisuales. Unos materiales que nuestros alumnos acogerán con agrado y expectación y que, bien usados, contribuirán a asentar en ellos el aprendizaje de los hechos históricos que en ellos se traten •

\section{Historia; recursos didácticos; medios audiovisuales; series de televisión; Ciencias Sociales.}

Este artículo fue solicitado por PADRES Y MAESTROS en marzo de 2020, revisado y aceptado en junio de 2020. 